\title{
Influência da origem da família e de variáveis econômicas no uso da terra e no desmatamento de lotes familiares da Amazônia brasileira
}

\section{The influence of family origin and economic variables in land use and deforestation of family plots in Brazilian Amazonia \\ Luciano Mattos - Doutor em Desenvolvimento Econômico, pela Universidade Estadual de Campinas (Unicamp) e pesquisador da Empresa Brasileira de Pesquisa Agropecuária (Embrapa). E-mail: luciano.mattos@embrapa.br}

Eduardo Brondízio - PhD em Ciências Ambientais e Antropologia pela Indiana University; Professor e Chefe do Departamento de Antropologia da Indiana University, USA. E-mail: ebrondiz@indiana.edu Ademar Romeiro - PhD em Economia pela Universidade de Paris; Professor do Instituto de Economia da Universidade Estadual de Campinas (Unicamp). E-mail: ademar@eco.unicamp.br

Rodrigo Orair - Mestre em Economia pela Universidade Estadual de Campinas (Unicamp); Pesquisador do Instituto de Pesquisa em Economia Aplicada (IPEA). E-mail: rodrigo.orair@ipea.gov.br

\section{Resumo}

O artigo compara a influência de onze variáveis independentes (origem da família, tempo de ocupação do lote, escolaridade do casal, índice de geração, índice de gênero, tamanho do lote, titularidade do lote, renda familiar anual, acesso ao crédito rural, acesso ao transporte e acesso à energia elétrica) no uso da terra e desmatamento de, aproximadamente, 2.400 lotes familiares rurais amazônicos selecionados pela política pública federal piloto Programa de Desenvolvimento Socioambiental da Produção Familiar Rural (Proambiente). O estudo discute as seis variáveis independentes que demonstraram influência estatisticamente significativa no desmatamento. $\mathrm{O}$ trabalho objetiva oferecer dados para a literatura e colaborar com o Proambiente, um importante programa governamental que une transição agroecológica e prestação de serviços ambientais para a sociedade.

\section{Palavras-chave}

Agricultura familiar. Reserva legal. Uso da terra. Desmatamento. Proambiente. Amazônia.

\begin{abstract}
This article examines the influence of eleven independent variables (family origin, time of lot's occupation, couple's schooling, generational index, gender index, size of lot, land tenure, annual family income, access to rural credit, access to transportation, access to electricity) on land use and deforestation of circa 2,400 lots selected by the pilot federal public policy Program for Social and Environmental Development of Rural Family Production (Proambiente). This article discusses six independent variables that demonstrated significant statistical influence in the deforestation. This study aims to contribute to the literature and offer subsidies to Proambiente, an important federal public policy developed in Brazilian Amazonia that unites agroecological transition and supply of environmental services to the society.
\end{abstract}

\section{Keywords}

Family agriculture. Legal reserve. Land use. Deforestation. Proambiente. Amazonia. 


\section{INTRODUÇÃO}

O presente artigo discute seis variáveis independentes entre onze estudadas por Mattos (2010) que apresentaram influência estatisticamente significativa no desmatamento da reserva legal de, aproximadamente, 2.400 lotes familiares localizados em sete sub-regiões da Amazônia brasileira e selecionados pela política pública federal piloto Programa de Desenvolvimento Socioambiental da Produção Familiar Rural (Proambiente). A legislação ambiental brasileira define "reserva legal" como a quantidade relativa de cobertura florestal que deve ser conservada por todas as propriedades rurais, percentual que varia conforme o bioma onde se localiza a unidade produtiva. No caso do bioma amazônico, $80 \%$ da área devem deter reserva legal. Já o Proambiente, de acordo com Mattos (2010), foi proposto pelos principais movimentos sociais rurais amazônicos em 2003, no primeiro ano do Governo Lula, como estratégia de harmonizar a transição agroecológica, a conservação ambiental e a prestação de serviços ambientais para a sociedade. Ainda que o governo federal brasileiro não tenha dado a prioridade esperada na definição de um marco legal que viabilizasse a remuneração de serviços ambientais, o Proambiente se apresenta como uma iniciativa relevante que proporciona o planejamento econômico ecológico dos lotes e a formalização de acordos comunitários para a prestação de serviços ambientais em escala de paisagem rural. O programa elenca os serviços ambientais de desmatamento evitado, sequestro de carbono, conservação do solo e da água, preservação da biodiversidade e redução da inflamabilidade da paisagem rural.

Mattos (2010) demonstra que entre onze variáveis independentes [“origem da família", "tempo de ocupação do lote", "escolaridade do casal”, "índice de geração" (relação entre potencial de trabalho e demanda de consumo no lote), "índice de gênero" (relação entre potencial de trabalho masculino e feminino no lote), "tamanho do lote", "titularidade do lote", "renda familiar anual", "acesso ao crédito rural", "acesso ao transporte para escoar produção" e "acesso à energia elétrica pra beneficiar a produção"], apenas seis [“origem da família”, "tempo de ocupação do lote", "tamanho do lote", "renda familiar anual", "acesso ao crédito rural" e "acesso à energia elétrica pra beneficiar a produção"] são estatisticamente significativas no desmatamento de reserva legal (PCT < 0,100). Essa análise não considera as diferenças sub-regionais, sendo os dados interpretados de forma agregada.
Desta feita, o presente estudo objetiva não somente oferecer dados para a literatura sobre desmatamento, mas também colaborar com o aprimoramento do Proambiente, que busca inovar ao unir co-gestão e co-execução entre o governo federal e a sociedade civil organizada da Amazônia, na busca de um novo conceito de serviços ambientais atrelado ao processo produtivo sob transição agroecológica e conservação ambiental. Entretanto, vale a ressalva que não se pretende atribuir responsabilidade sobre o desmatamento da Amazônia brasileira aos agricultores familiares da região, especialmente aos cadastrados pelo Proambiente, que foram selecionados por dois critérios de capital social, sendo eles (a) nível de experiência na execução de projetos governamentais e não governamentais e (b) existência e participação em associações comunitárias, ações que buscam práticas alternativas de uso da terra e dos recursos naturais. Logo, pretende-se demonstrar as variáveis independentes mais relevantes a serem trabalhadas por políticas públicas para mitigar os processos de desmatamento em lotes familiares rurais da Amazônia.

Ao comparar os índices estaduais de desmatamento no Brasil, em 2003, remetendo-se aos dados do Instituto Nacional de Pesquisas Espaciais - Projeto de Monitoramento do Desflorestamento na Amazônia Legal (INPE-PRODES), Brondízio et al. (2009a) constatam que para os estados do Pará, Acre e Rondônia, os pequenos desmatamentos (até 20 hectares) são os tipos mais frequentes, correspondendo a, aproximadamente, $88,1 \%$ do número total de abertura de florestas no Acre, $74,0 \%$ no Pará e 73,2\% em Rondônia. Entretanto, quando considerada a área desmatada, as mesmas representam somente 7,6\%, 3,2\% e 2,1\%, respectivamente, do total de desmatamento desses estados. Por sua vez, os grandes desmatamentos (maiores que 2.000 hectares) abrangem, aproximadamente, $0,10 \%$, 0,47\% e 0,40\% do total de eventos no Acre, Pará e Rondônia, respectivamente, mas contabilizam correspondentes $86,0 \%, 91,2 \%$ e 94,5\% do total de área desmatada. Assim, a maior porcentagem de eventos de desmatamento e a menor quantidade absoluta desmatada correspondente às propriedades familiares rurais evidenciam tanto a responsabilidade principal do desmatamento da Amazônia brasileira às propriedades patronais rurais quanto a importância de propriedades familiares na fragmentação da paisagem regional.

São relevantes os contrapontos de Batistella (2001) e Batistella et al. (2003) de que o alto número de eventos de desmatamentos da agricultura familiar, embora relativamente pequenos em área total, também podem trazer importantes implicações para as mudanças ambientais e para a própria sustentabilidade de 
seus sistemas produtivos, dependendo do contexto de cada paisagem local. Em áreas de agricultura familiar, o desenho de projetos de colonização e os arranjos institucionais contribuem para o padrão espacial do desmatamento que ocasiona depleção dos recursos naturais e erosão de solos, além de uma gama importante de incêndios florestais acidentais.

Outro ponto a destacar é que na maioria das circunstâncias inexiste a associação positiva entre o tamanho da propriedade e o rendimento por área, o que eleva a importância da desconcentração fundiária (RAMOS, 2001). Os dados dos estabelecimentos rurais brasileiros demonstram, inclusive, uma relação inversa entre tamanho e renda, onde destacadamente são os empreendimentos familiares rurais os mais rentáveis na relação entre Valor Bruto de Produção Agropecuária e unidade de área. Porém, é fundamental ter em mente que dentro do recorte restritamente familiar essa relação se torna direta, com o tamanho do lote sendo relevante na geração de renda. Minifúndios ou porções muito reduzidas de terra demandam alta intensificação de sistemas produtivos (pois a pecuária, que alavanca a capitalização familiar, necessita de áreas mais abrangentes) para se tornarem economicamente viáveis, cenário que comumente diverge da realidade do contexto produtivo familiar rural amazônico e põe em risco o próprio processo de reprodução social da família e da capacidade de reter eventos de desmatamento (MATTOS, 2010).

Em seu estudo, Mattos (2010) levantou como hipóteses que o atendimento aos princípios de uso econômico ecológico da terra e dos recursos naturais do Proambiente (transição agroecológica associada à conservação de reserva legal) vem de famílias com (a) origem na Amazônia Legal (conhecimento empírico do bioma), (b) mais tempo de ocupação do lote, (c) maior tamanho de lote, (d) renda familiar anual superior, (e) acesso ao crédito rural e (f) acesso à energia elétrica para beneficiar a produção (pois os cinco últimos quesitos possibilitam maior capacidade de investimento em sistemas agroecológicos associados com retenção ou recuperação de reserva legal). A seguir é apresentada uma revisão da literatura que contempla dados sobre a influência das seis variáveis independentes citadas acima no desmatamento de lotes familiares rurais da Amazônia brasileira, assim como o teste das hipóteses acima baseado nos resultados obtidos por Mattos (2010).

\section{IMPORTÂNCIA DO ESTUDO DE VARIÁVEIS DE DESMATAMENTO DA AMAZÔNIA EM ESCALAS INTRA E INTER-REGIONAIS}

Desde a década passada, em diversas revistas científicas, artigos têm voltado a atenção para as causas e consequências do desmatamento da Amazônia, com a característica comum de fazer uma análise do bioma. Essa perspectiva oferece importantes conclusões, tais como a conexão entre a construção de estradas e desmatamento. No entanto, esse enfoque regional esconde diferenças inter e intrarregionais que desaparecem estatisticamente quando os dados são agregados (MORAN et al., 2009). Este trabalho representa um passo intermediário, pois abrange sete sub-regiões de forma agregada (com mais detalhamento em relação ao bioma como um todo, mas ainda sem um alcance específico de cada sub-região), para em estudos futuros se voltar às particularidades de cada sub-região.

Poucos lugares na Terra têm sido tão diretamente afetados política e economicamente pelas mudanças de uso e cobertura da terra como a Amazônia. Logo, o desafio de incorporar as diversidades inter e intrarregionais quando se considera a bacia amazônica, no contexto atual, assume grande relevância política, econômica e ecológica. Com o ambiente global em foco, o principal paradoxo da pesquisa sobre população e meio ambiente é que as generalizações necessárias para obter uma perspectiva global negligenciam importantes detalhes locais. Embora os macroprocessos continuem extremamente importantes, a expansão da mudança não pode ser generalizada em função da diversidade de variações socioculturais inter e intrarregionais, da história sociocultural de cada local, das formas de superação da baixa produtividade marginal do trabalho, dos arranjos econômicos e das características ambientais de paisagens rurais subjacentes ao uso da terra. Destacar os fatores que mediam os níveis macro e micro contribuem para a compreensão do desenvolvimento rural da Amazônia, incluindo os processos de desmatamento, os ciclos econômicos, os arranjos de trabalho e o controle de capital (BRONDÍZIO, 2009, p. 290).

O presente estudo abrange a análise local detalhada de todos os 2.400 Planos de Utilização das Unidades de Produção (PUs) selecionadas pelo Proambiente, o que representa uma amostra de $83 \%$ do programa e significativos $0,43 \%$ dos lotes da Amazônia Legal. Como seis variáveis independentes demonstraram significância estatística, a discussão adiante as separa, pois passa a ser mais relevante interpretálas individualmente a compará-las entre si num mesmo bloco (ver dados analisados no Quadro 1 e na Tabela 1). 

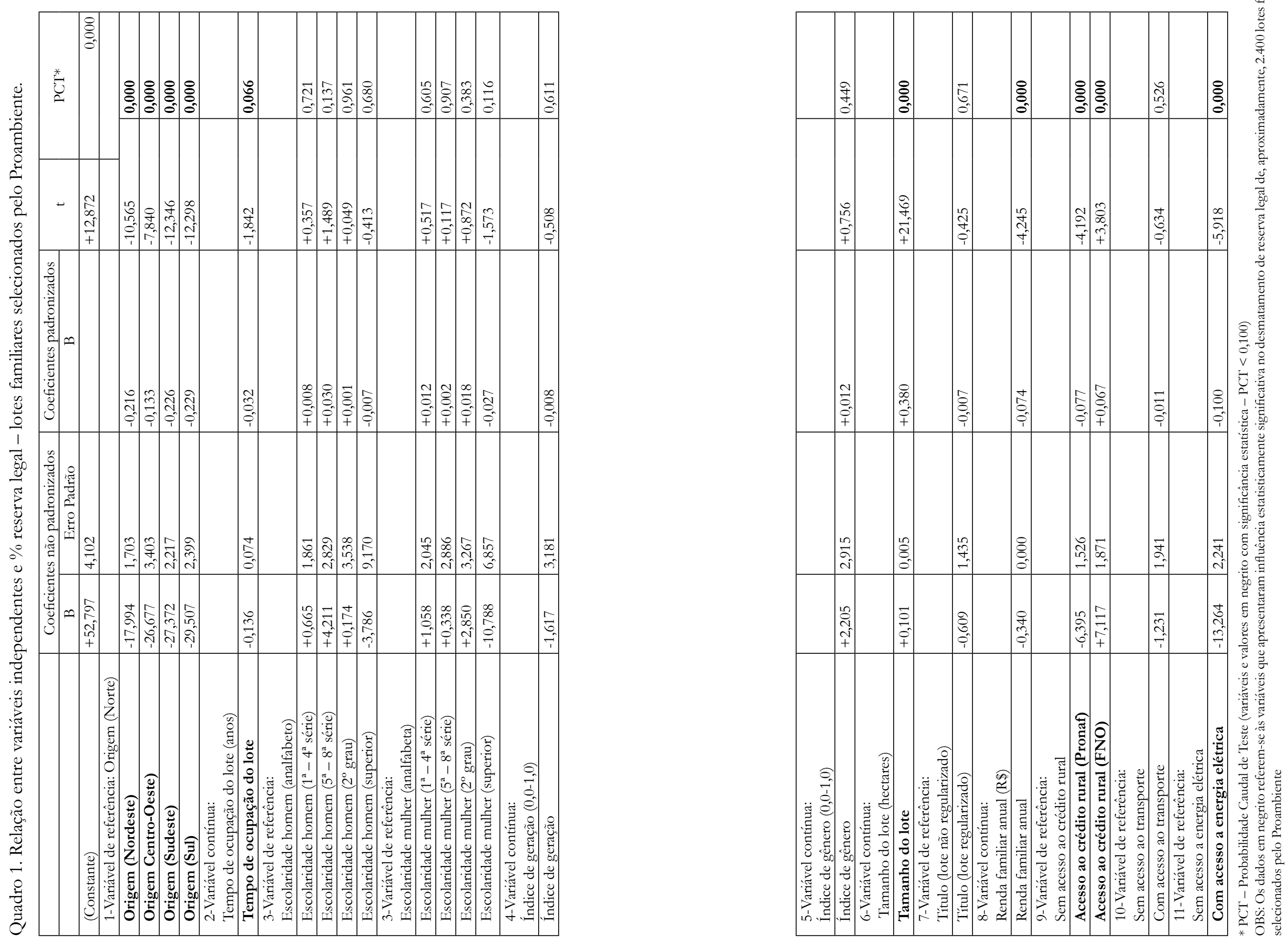

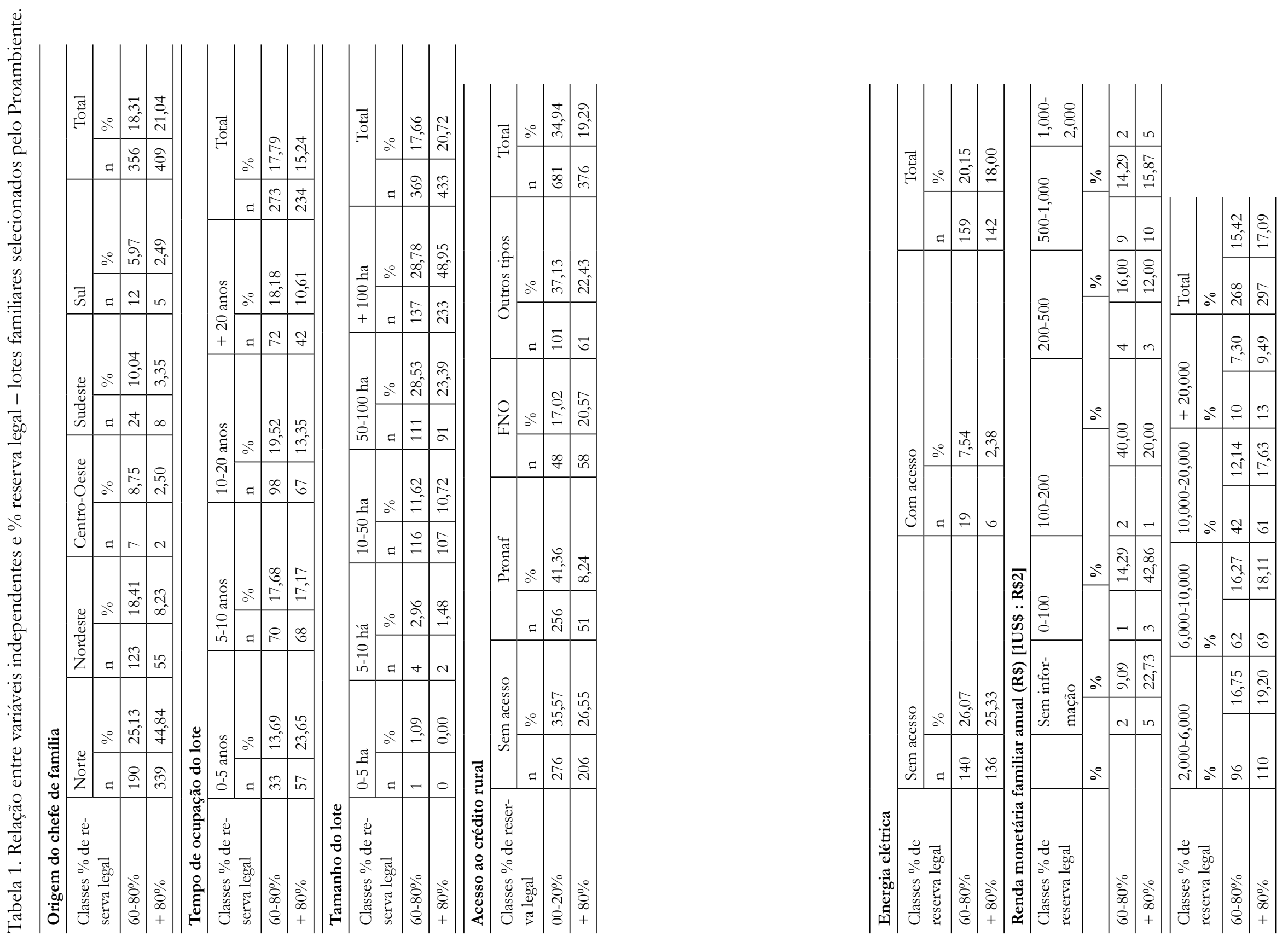


\section{ORIGEM DO CHEFE DE FAMÍLIA}

As bases culturais da prática produtiva e da sensibilidade ecológica de um agricultor familiar se atrelam, em parte, à sua região de origem, e aliadas às condições objetivas de disponibilidade de recursos naturais, pode constituir-se numa vantagem ou desvantagem a fundamentar, no contexto dado, dinâmicas de mudanças de uso da terra em busca de maior eficiência produtiva e ecológica (CARVALHO, 2000; MATTOS, 2010).

As racionalidades produtivas e as diferentes identidades de colono, que podem ser definidas como ethos de colono, tencionam esferas relacionais ao mesmo tempo em que acomodam situações internas e externas conforme as suas experiências vividas. Quando falamos em ethos, estamos falando de representações culturais inseridas, produzidas e emitidas sobre o vivido e a realidade social e ecológica na qual o indivíduo está inserido, socializado, e que também influencia o seu comportamento sobre o uso da terra e dos recursos naturais (TEDESCO, 2001).

Quando falamos de um ethos de colono, não estamos querendo apresentar um modo coerente e estanque de uma lógica de reprodução local, apoiada em uma produção de subsistência ausente de vínculos mercantis. A noção de ethos de colono está envolto, em parte, numa economia moral que não exclui uma racionalidade econômica interna a seu ambiente vivido e concebido, com características objetivas, pragmáticas e racionais do universo econômico mais amplo (WOORTMANN, 1990). Por isso é necessário dar ênfase aos aspectos socioculturais e ecológicos imbricados com as dinâmicas econômicas e com o espaço da família rural.

Muitos estudos têm caracterizado as diferenças culturais pela maneira como as pessoas concebem e relacionam-se com o meio ambiente, isto é, como encampam modos de identificação e de interação entre seres humanos e natureza (BRONDÍZIO et al., 2009b). Portanto, estudar a influência da variável origem torna-se relevante não para comparar de forma determinística tipos mais viáveis de uso da terra e dos recursos naturais, aptidão agrícola ou capacidade de trabalho conforme a região nativa da família rural, mas para construir uma leitura de como a diferença de origem é relevante nas suas decisões. Esse tipo de resposta é importante para subsidiar a construção de políticas públicas que contemplem as diferentes experiências com sistemas produtivos, conhecimento dos ecossistemas, expectativas econômicas e preferências na formação da paisagem local (MATTOS, 2010).
Segundo Van der Plog (2006), os recursos sociais e materiais disponíveis representam uma unidade orgânica e são possuídos e controlados por aqueles diretamente envolvidos no processo de trabalho. As regras que governam as interrelações entre os atores envolvidos (e que definem suas relações com os recursos mobilizados) são tipicamente derivadas de (e vinculadas aos) repertórios culturais locais. Pan e Bilsborrow (2005) identificam três perspectivas no entendimento da interação entre população e meio ambiente: (a) interpretação histórica e cultural; (b) leitura do comportamento individual quanto às tomadas de decisão; e (c) entendimento das regras que circulam em torno das instituições e que estabelecem as oportunidades e restrições quanto às tomadas de decisão.

No início da expansão amazônica, os amazônidas tendiam a explorar o ambiente florestal em paralelo à agricultura anual, numa economia baseada em uma grande variedade de frutas e produtos florestais não madeireiros. Por outro lado, agricultores familiares de origem sulista, com forte tradição agrícola e pecuária, além de pouco conhecimento florestal, apoiaram-se no crédito rural subsidiado para formação de seus lotes (LUDEWIGS, 2006). No entanto, isso não quer dizer que um agricultor originário de uma ou outra região possua mais ou menos habilidades agronômicas, mas apenas ilustra os vários modos particulares de uso da terra e dos recursos naturais (MORAN, 1981).

Brondízio (2009) lembra que as interpretações etnobotânicas distinguem os amazônidas dos migrantes por meio da leitura do potencial econômico das florestas perante sua conversão via desmatamento. Por outro lado, a criatividade dos migrantes para desenvolverem sistemas agroflorestais gera oportunidades para conciliar o manejo florestal e o uso econômico da terra em programas de desenvolvimento rural. Mattos (2010) também diagnostica maior quantidade de reserva legal e menor de cultivos perenes em lotes de famílias amazônicas. Mas, a maior dificuldade dos produtos florestais em relação aos agropecuários no acesso aos mercados consumidores ajuda a explicar a renda inferior dos amazônidas, além de expressar a falta de políticas de indução de demanda florestal.

De acordo com dados de Moran (1981), após três anos de ocupação, os sulistas eram os que detinham a maior porção desmatada e um forte direcionamento pecuário, seguidos dos agricultores originários do Centro-Oeste. Já os nortistas amazônidas se enquadravam entre os com menor tradição pecuária, devido aos seus modos particulares de uso da terra e dos recursos naturais. Esses resultados são corroborados por Mattos (2010), que aponta o viés pecuário aos produtores 
do Sudeste, Sul e Centro-Oeste, e de conservação de reserva legal dos produtores do Norte.

Segundo Walker et al. (2002), a forma de sustento diversificada dos amazônicos pode contribuir para o aumento da resiliência de sistemas de produção. Dessa forma, sistemas múltiplos apresentam não somente potencial econômico, mas também ecológico, sendo possível integrá-los na averbação de reserva legal. Também para Moran et al. (2009), as diferenças socioeconômicas afetam as dinâmicas regionais do desmatamento, pois se os migrantes são nativos da Amazônia (devido a processos de migração intrarregional), a probabilidade de manterem padrões de desmatamento mais amenos será maior que a dos migrantes de regiões não amazônicas, com outros sistemas de produção e outras tradições de manejo de recursos naturais.

Ludewigs (2006) encontrou que em assentamento rural localizado em Humaitá (estado do Acre), os lotes de amazônicos mantêm maior percentual de terras com cobertura florestal, florestas secundárias e cultivos anuais, enquanto cultivos perenes e atividade pecuária são mais significativos em lotes de migrantes com origem externa à região amazônica. Os migrantes também demonstraram proporções mais altas de terras recentemente abandonadas quando comparados com os amazônicos, o que pode indicar sua maior dificuldade em manter pastos limpos, enquanto lotes de amazônicos apresentaram proporção média de cobertura florestal, em 2003, em torno de 14\% acima das médias verificadas em lotes de migrantes.

Para a variável independente "origem da família", Mattos (2010) levantou como hipótese que o atendimento aos princípios de uso econômico ecológico da terra do Proambiente vem de famílias com origem na Amazônia Legal devido ao seu conhecimento ecológico empírico do bioma. O estudo do autor demonstra que lotes liderados por famílias originárias da Amazônia claramente se sobressaem, pela maior quantidade de reserva legal em relação aos liderados por famílias de migrantes. Na classe de porcentagem de 60-100\% de reserva legal, 69,97\% dos lotes de famílias do Norte concentram cobertura florestal, contra apenas 26,64\% do Nordeste, $13,39 \%$ do Sudeste, $11,25 \%$ do Centro-Oeste e $8,46 \%$ do Sul. Ao se restringir mais a análise para o que estabelece a legislação ambiental no bioma amazônico (mínimo de 80\% de reserva legal) é possível constatar que 44,84\% dos lotes de amazônicos estão na legalidade, contra somente $8,23 \%$ do Nordeste, 3,35\% do Sudeste, 2,50\% do Centro-Oeste e 2,49\% do Sul. Portanto, há uma clara relação entre origem da família e preservação de reserva legal, explicável pela tradição agroextrativista dos amazônicos e pela tradição agropecuária dos produtores das demais regiões. Para a relação entre origem da família e reserva legal, a hipótese se confirma.

\section{TEMPO DE OCUPAÇÃO DO LOTE}

Para Brondízio et al. (2009a), Van Wey et al. (2009), McCracken et al. (1999) e Walker (2003), as unidades domésticas evoluem, geralmente, a partir de unidades nucleares com crianças pequenas para unidades com adolescentes e jovens adultos (a) que deixam a casa dos pais em busca de unidades próprias ou (b) que formam famílias extensas com múltiplas gerações. À medida que ocorrem as mudanças, as necessidades de consumo (determinadas pelo número de membros da unidade, particularmente pelo número de dependentes) e a força de trabalho disponível (determinada pelo número de membros em idade economicamente ativa) também mudam. Neste modelo conceitual, a unidade primeiramente se concentra na derrubada da mata e no cultivo de culturas anuais, para nos estágios seguintes se dedicar a usos da terra que oferecem dividendos menores de curto prazo e maiores de longo prazo. Essa perspectiva teórica propõe que o uso da terra e dos recursos naturais (particularmente a extensão desmatada) variam entre as unidades (dentro de uma comunidade), basicamente em função do tempo de ocupação e da composição familiar das unidades produtivas ao longo do tempo.

Mattos (2010), assim como os autores acima, reconhecem que as taxas de desmatamento não são relacionadas somente com os diferentes tempos de ocupação do lote e com as mudanças na composição familiar, mas também com a disponibilidade de capital e tecnologia e com as estratégias de uso da terra e dos recursos naturais, que são amadurecidas na evolução do processo de colonização de uma fronteira agrícola.

Pan et al. (2007) e Brondízio et al. (2002) notaram que a relação positiva entre o tempo de ocupação do lote e o desmatamento não é estritamente casual no espaço e no tempo de diferentes grupos de migrantes da Amazônia. Famílias com mais tempo nos lotes apresentam, em geral, maiores porções de áreas desmatadas, contudo, o tipo de floresta usada varia ao longo do tempo, isto é, núcleos familiares a mais tempo assentados tendem a usar espacialmente, de forma mais significativa, 
as florestas secundárias quando comparadas com núcleos familiares recém-egressos de seu local de origem, os quais direcionam seus esforços na abertura de florestas primárias.

Em estudos similares, Brondízio et al. (2009a), Perz e Walker (2002) e Perz (2001) observaram que significativas porções de áreas desmatadas geralmente ocorrem em propriedades rurais compostas por famílias com substancial capacidade de trabalho, incluindo trabalho familiar próprio (que se potencializa ao longo do tempo de ocupação do lote), contratado temporário ou sob trocas de diárias.

Para McCracken et al. (2002), agricultores familiares assentados ao longo na rodovia Transamazônica (estado do Pará) no início dos anos 70 detinham, aproximadamente, 55\% de taxa de desmatamento em seus lotes em 1985, sendo esta área sob solo nu (para o plantio de cultivos anuais), pastagens ou florestas secundárias em vários estágios sucessionais. Em 1988, um adicional médio de $4 \%$ da área havia sido desmatado, enquanto a área de solo nu e pastagens havia levemente regredido e a área de florestas secundária avançado em $40 \%$ do lote. Os autores assumem que o uso da terra e dos recursos naturais (e o consequente ritmo de desmatamento) é influenciado também pelas políticas públicas, mercado consumidor e tendências econômicas. Isso significa que a paisagem rural depende de um mosaico de propriedades rurais em diferentes estágios de ocupação humana que reagem num mesmo momento conforme suas condições estruturais. Além do acesso ao crédito rural e ao mercado consumidor, os autores encontraram que a origem da família e o tempo de ocupação do lote aparecem como variáveis relevantes.

Brondízio et al. (2002) e McCracken et al. (1999) usaram sensoriamento remoto para mensurar a relação entre o tempo de ocupação do lote (desde o tempo zero ou momento de abertura das propriedades) e a cobertura florestal, relacionando esses fenômenos ao ciclo de vida familiar. Os autores encontraram evidências de mudanças nas taxas de desmatamento ao longo do ciclo de vida familiar, com taxas amenas no início da ocupação, seguido de um primeiro pico de desmatamento entre 3-5 anos e segundo pico entre 10-15 anos.

Para Moran et al. (2009) e Brondízio et al. (2002), depois de cerca de cinco anos (em média), enquanto os agricultores familiares consolidam e usam áreas já desmatadas, ocorre um segundo aumento do desmatamento, dado por uma nova fase de expansão das atividades nos lotes, a qual pode dar origem a novas áreas de cultivos anuais e perenes e de pastagens, dependendo da relação capital-trabalho e da disponibilidade de terra e água.

Segundo McCracken et al. (1999), o espaço de tempo entre a ocupação do lote e a consolidação dos sistemas de produção apresenta uma curva inicial crescente, seguida de uma curva estável de desmatamento. Portanto, o tempo de ocupação do lote é uma variável relevante para o processo de desmatamento e regeneração de áreas de capoeira.

Brondízio et al.(2002) expõe que o processo de desmatamento tende a ser mais intenso nos cinco primeiros anos de assentamento, devido à necessidade de se estabelecer os sistemas produtivos anuais, mas depois de alguns anos, a taxa tende a decrescer, mas volta a subir adiante com a introdução da atividade pecuária e a se estabilizar ou decrescer levemente com a consolidação de sistemas perenes em áreas de floresta secundária, que podem ser usados para averbação de reserva legal.

Outro fator a ser considerado na relação entre tempo de ocupação do lote e desmatamento refere-se à rotatividade de famílias num mesmo lote. Conforme demonstram Van Wey et al. (2007) e Schmink e Wood (2002), em meados dos anos 70 , muitos agricultores familiares que reclamavam o título da terra abandonaram seus lotes, em parte já desmatados, devido à falta de condições econômicas de produção e de segurança pública. Ludewigs et al. (2009), Moran et al. (2002) e Smith (1982) ilustram que no final dos anos 70, apenas uma década após o início da ocupação amazônica, 19\% dos lotes em Marabá e 30\% em Altamira (ambos no estado do Pará) já tinham sido abandonados pelos proprietários originais. Ludewigs (2006) argumenta que enquanto a rotatividade da terra pode interromper a relação entre ciclo de vida familiar e uso da terra e dos recursos naturais, ela não necessariamente interrompe o ciclo do lote em si, ao revés, tende a mantê-lo. Por esse motivo é que esse fenômeno é de complexa mensuração, vide o caso do estudo de Pan e Bilsborrow (2005), onde não foi encontrada relação significante entre tempo de ocupação do lote e uso da terra. Apesar dos incentivos oficiais, Romeiro (1998) também observou uma rotatividade elevada de donos de lotes ao longo do tempo de ocupação, fenômeno característico das regiões de fronteiras agrícolas que varia conforme as diferentes épocas e zonas, sem que suas causas estejam claramente identificadas e hierarquizadas. Por isso, Mattos (2010) salienta que a alta rotatividade demonstra-se como indicador do insucesso da estratégia geopolítica dos governos militares de criar um ambiente produtivo aos agricultores familiares amazônicos. 
Para a variável independente "tempo de ocupação do lote", Mattos (2010) assumiu como hipótese que o atendimento aos princípios de uso econômico ecológico da terra do Proambiente vem de famílias com mais tempo de ocupação do lote devido à maior capacidade de investimento em sistemas agroecológicos associados com retenção ou recuperação de reserva legal. $\mathrm{O}$ autor encontrou relação negativa entre tempo de ocupação do lote e quantidade de reserva legal. $\mathrm{Na}$ classe de porcentagem de $60-100 \%$ de reserva legal, há queda ao longo do tempo de 37,34\% (0-5 anos) para 34,85\% (5-10 anos), 32,87\% (10-20 anos) e $28,79 \%$ (mais de 20 anos) dos lotes, sendo que dentro da legislação ambiental no bioma amazônico (mínimo de $80 \%$ de reserva legal), a queda é mais acentuada, de $23,65 \%$ para $13,35 \%$ ao longo de 20 anos, e para 10,61\% para mais de 20 anos. Para reserva legal, a hipótese não se confirma, ainda que o crescimento de cultivos perenes verificado nos lotes possa ser utilizado para averbação de reserva legal. A não confirmação da hipótese também se associa com a alta rotatividade de famílias nos lotes, que desencadeiam novos processos de desmatamento.

\section{TAMANHO DE LOTE}

Dados de Guanziroli et al. (2001), trabalhados a partir do Censo Agropecuário do Brasil 1995/96, demonstram que os lotes da agricultura familiar da região amazônica detém o segundo maior tamanho médio nacional, em torno de 57 hectares, abaixo apenas da região Centro-Oeste com 84 hectares, e acima das regiões Sudeste com 30 hectares, Sul com 21 hectares e Nordeste com 17 hectares. No Brasil como um todo, o tamanho médio do lote familiar gira por volta de 26 hectares, menos da metade da média amazônica. Mas, como alerta Arima (2000), o tamanho dos lotes é bastante variado dentro da Amazônia, sendo menores nas áreas de fronteiras agrícolas antigas e maiores nas fronteiras agrícolas recentes. Três características do uso da terra merecem ser destacadas: (1) a quantidade proporcional de capoeira (crescimento de vegetação secundária que sinaliza desmatamento) é maior nos lotes de ocupação antiga; (2) a quantidade proporcional de florestas primárias e exploradas é maior nos lotes de ocupação recente; (3) a expansão da pecuária (e consequente desmatamento) nos lotes de ocupação recente é notável, pois a disponibilidade de área e a precária infraestrutura tornam a atividade uma opção econômica mais interessante.
Mattos (2010) evidencia em seu estudo esta relação entre tamanho dos lotes e idade da fronteira agrícola. Conforme ilustra o autor, as fronteiras agrícolas mais antigas, com terras a preços valorizados devido à infraestrutura estabelecida, apresentam tamanhos de lotes mais reduzidos, enquanto as novas fronteiras agrícolas podem congregar lotes entre 100 e 400 hectares, fato que impacta fortemente o perfil sub-regional de cada propriedade familiar. Ao comparar os dados de sete sub-regiões contempladas pelo Proambiente, Mattos (2010) demonstra que os lotes selecionados pelo programa detêm maiores porções de terra na nova fronteira agrícola, isto é, no Alto Acre (estado do Acre), com média de 281 hectares e na Transamazônica (estado do Pará), com 94 hectares. Para o primeiro caso, ressalta-se a particularidade de contemplar tanto áreas de uso agrícola individual quanto reservas extrativistas coletivas, o que eleva sua média. Já nas subregiões localizadas em fronteiras agrícolas mais antigas, os lotes são menores, com média de 19 hectares na Baixada Maranhense (estado do Maranhão, com maior percentual de minifúndios do país), 33 hectares no Noroeste (estado do Mato Grosso), 35 hectares em Ouro Preto D’Oeste (estado de Rondônia) e 38 hectares no Bico do Papagaio (estado do Tocantins). A exceção fica para o rio Capim (estado do Pará), que detém lotes com médias de 43 hectares, embora esteja localizado na área de fronteira agrícola mais antiga da Amazônia. O fato se explica por dois motivos: (a) pelo seu histórico de ocupação provinda de migrantes nordestinos no final do século 19 e início do século 20, que consolidou precocemente a subregião (meio século antes do início da expansão da fronteira agrícola amazônica) como produtora de alimentos, à frente de exploração da borracha amazônica, um dos dois produtos de exportação mais importantes do país, junto ao café paulista naquele momento; (b) a confirmação de seu perfil produtivo familiar sustentado também devido à localização próxima à zona metropolitana de Belém (capital do estado do Pará), um mercado consumidor de dois milhões de pessoas.

Dados de Carvalho (2000), Guanziroli et al. (2001), Ludewigs et al. (2009) e Mattos (2010), em diferentes estudos, também apontam que a quantidade de trabalho relacionada com o tamanho da área cultivada em lotes familiares amazônicos determina a intensidade do sistema produtivo e os processos de desmatamento. A respeito do sistema produtivo, de maneira geral, com mais terra e menos trabalho, mais extensivo será o sistema produtivo, ao passo que com menos terra e mais trabalho, mais intensivo será o sistema produtivo. Em alguns casos, a disponibilidade de área por trabalhador é tão ampla que não se justifica a 
introdução de sistemas intensivos, sendo priorizada a introdução de sistemas que garantam uma boa produtividade do trabalho, mesmo que com baixa rentabilidade por unidade de área. Ao revés, quanto menor a disponibilidade de área, maior a importância relativa de cultivos altamente exigentes em mão de obra e altamente intensivos no uso da terra e dos recursos naturais. Já em consideração aos processos de desmatamento, lotes menores apresentam taxas proporcionais maiores de desmatamento, pois são cultivados a mais tempo, desse modo, passaram por processos sucessivos de fragmentação, assim como há uma demanda uniforme de área para cultivo de anuais para subsistência (arroz, feijão, milho e mandioca), que toma uma área proporcionalmente maior do lote com dimensões mais reduzidas.

$\mathrm{Na}$ escala de propriedades, Moran et al. (2009) demonstra que as condições iniciais do lote que favorecem ou não a produtividade da terra e do trabalho e o uso de tecnologias explicam o padrão espacial do desmatamento, enquanto a intensidade temporal é definida pelo tamanho da unidade, composição de mão de obra doméstica e acesso a fontes de capital, assim como a objetivos de curto e longo prazos de seus residentes.

Análises de Pan et al. (2004) indicam alta divisão de terras de colonização espontânea, entre 1990 e 1999, na Amazônia equatoriana. Inicialmente alocados em lotes com média de 50 hectares, a área estudada passou por processo de subdivisão de lotes devido à chegada de novos colonos atraídos pela economia do petróleo alavancada na região. Assim, os antigos proprietários rurais negociaram parte de suas terras com os novos colonos recém-egressos de outras partes do país, fenômeno que elevou a densidade demográfica local e causou aumento de desmatamento e de área de pastagens, além de aumento concomitante da área com cultivos anuais e perenes. Já os mesmos lotes estudados por Pan e Bilsborrow (2005), que não passaram por subdivisão, ainda detinham 56,1\% da cobertura florestal no ano de 1999, enquanto lotes que passaram por uma ou duas subdivisões tinham $47,0 \%$ e $32,0 \%$, respectivamente, de floresta primária.

Brondízio et al. (2009a), em estudo na sub-região de Santarém (estado do Pará), detectaram que a maioria dos agricultores familiares com lotes de até 10 hectares mantém, no mínimo, $25 \%$ de suas terras com cobertura florestal, enquanto aqueles que detêm lotes entre 10-20 hectares mantêm, aproximadamente, $40 \%$ ou mais, e os posicionados entre 20-50 hectares mantêm mais de 50\%. De forma similar, ao estudarem a relação entre tamanho do lote e desmatamento em lotes familiares, McCracken et al. (1999) encontraram que cada hectare adicional de cobertura florestal é positivamente relacionado com 0,05 hectares a mais de desmatamento anual, ou seja, um lote com 20 hectares a mais de floresta deverá desmatar, aproximadamente, um hectare a mais que a unidade de produção correspondentemente menor. Porém, a invariabilidade da área de cultivo anual, que gira em torno de 3-5 hectares por lote (devido à capacidade de trabalho), direciona para o desmatamento proporcionalmente menor em lotes com tamanho maior, salvo se o lote se caracterizar estritamente pela atividade pecuária.

Foi exatamente esta exceção que Mattos (2010) encontrou em estudo do Proambiente para o caso específico da sub-região da Transamazônica (estado do Pará), onde lotes maiores apresentam maior contingente de desmatamento devido ao perfil pecuário de muitas famílias. Com a necessidade de ampliar a margem extensiva da atividade pecuária, típica de lotes com maiores porções de terra, a área proporcional de reserva legal foi significativamente reduzida. Por outro lado, Brondízio et al.(2009a) explica que produtores familiares do estuário amazônico, com lotes proporcionalmente menores, cessaram o processo de desmatamento com o manejo florestal e os sistemas agroflorestais baseados no açaí devido à demanda crescente de mercados consumidores. Aqui de novo figura uma exceção, onde lotes menores detêm maiores contingentes de reserva legal devido à intensificação de uso da terra.

Para a variável independente "tamanho do lote", Mattos (2010) assumiu como hipótese que o atendimento aos princípios de uso econômico ecológico da terra do Proambiente vem de famílias com lotes proporcionalmente maiores devido à maior capacidade de investimento em sistemas agroecológicos associados com retenção ou recuperação de reserva legal. O autor encontrou dados emblemáticos que confirmam a relação positiva entre tamanho do lote e reserva legal. Estão dentro da legislação ambiental amazônica (mais de 80\% de reserva legal) 48,95\% dos lotes com mais de 100 hectares, $23,39 \%$ entre $50-100$ hectares, $10,72 \%$ entre 10-50 hectares, $1,48 \%$ entre 5-10 hectares e nenhum abaixo de 5 hectares, o que demonstra a relevância da discussão dos movimentos sociais rurais sobre diminuição dos limites ambientais legais para lotes inferiores a 100 hectares. Assim, no decorrer dos anos, há retirada de reserva legal, e de forma mais expressiva nos lotes menores. Contudo, há exceções, como da sub-região Transamazônica (estado do Pará), onde os lotes maiores detêm menor percentual de reserva legal devido à sua tradição pecuária, com substituição direta de reserva legal por pastagens. Para o tamanho do lote, a hipótese se confirma e evidencia a demanda por políticas integradas de produção agrícola e conservação ambiental. 


\section{RENDA FAMILIAR ANUAL}

Os dados disponíveis na literatura brasileira referentes à renda média monetária anual por estabelecimento familiar rural, que não considera o consumo das famílias e o consumo intermediário da alimentação animal, são um tanto quanto controversos. De acordo com Hoffmann (2003), a renda média monetária anual em lotes rurais amazônicas é de $\mathrm{R} \$ 4.707,11$, enquanto Guanziroli et al.(2001) registra um valor bem inferior de $\mathrm{R} \$ 2.904,00$. Seja apoiado nos dados de Hoffmann (2003) ou Guanziroli et al.(2001), Mattos (2010) observa que a maioria dos lotes familiares rurais amazônicas selecionados pelo Proambiente está num patamar equivalente $(33 \%)$ ou superior $(49,7 \%)$ de renda familiar monetária anual em relação à média do bioma.

Mattos (2010) e Graziano da Silva (1999) alertam que a redução relativa do crescimento do emprego rural estritamente agrícola em contraposição ao aumento do emprego rural não agrícola não pode ser interpretado, no caso da Amazônia, como indicadores de uma tendência estrutural de transformação do espaço rural análoga à que ocorrera nos países desenvolvidos.

Os empregos não agrícolas no espaço rural amazônico configuram-se muito mais num reforço às estratégias de uso da terra e dos recursos naturais dos agricultores familiares ante a histórica falta de infraestrutura e crédito rural de custeio e investimento suficiente para financiar a safra seguinte do que propriamente um êxodo da atividade agrícola (MATTOS, 2010). Portanto, as oportunidades de trabalho fora dos estabelecimentos rurais estão associadas ao que Dirven (2000) denomina de “ocupação refúgio". Sob a perspectiva de distribuição mais equânime das oportunidades de renda, o desafio que se coloca é superar o que Reardon et al. (1998) chamam de "paradoxo das ocupações rurais não agrícolas", isto é, são os estabelecimentos mais pobres os que mais necessitam de fontes adicionais àquelas que são geradas pela agricultura, porém, são justamente esses que enfrentam as maiores limitações de capital humano e produtivo, dificuldades para oferecer garantias de crédito rural e capacidade administrativa.

Guanziroli et al. (2001), Romeiro (1999) e Romeiro (1998) diferenciam os produtores familiares rurais em três categorias básicas de renda: (1) produtores familiares rurais capitalizados, com renda agrícola superior ao custo de oportunidade do trabalho, produção principalmente voltada para o mercado consumidor (embora dediquem parte para consumo próprio), acumulação de capital em maquinários, benfeitorias e/ou terra, disposição de recursos suficientes para a produção agrícola, renda agrícola confortável e relativamente afastados do risco de descapitalização ou de eliminação do processo produtivo; (2) produtores familiares em via de capitalização, com renda agrícola entre o nível de subsistência e o custo de oportunidade do trabalho, produção principalmente voltada para a subsistência (ainda que em ascensão para o mercado consumidor), amena acumulação de capital e renda ainda insuficiente para mantê-los afastados do risco de descapitalização ou de eliminação do processo produtivo; (3) produtores familiares descapitalizados, com renda agrícola inferior ao nível de subsistência, produção voltada para o consumo próprio, sem acumulação de capital e renda sob risco de eliminação do processo produtivo.

Para Mattos (2010) e Guanziroli et al. (2001), a elevação do custo de oportunidade não leva, necessariamente, à eliminação da agricultura familiar, a qual dispõe de alternativas tecnológicas que permitem elevar a produtividade do trabalho e o nível de renda dos estabelecimentos agropecuários paripassu à elevação do custo de oportunidade. E para Schultz (1965), o desafio consiste em determinar quão baixos podem ser os custos de oportunidades do trabalho e quanto de crescimento pode ser obtido para cada tipo de investimento. O que se deve ter em mente, portanto, é que a agricultura familiar apresenta demandas gradativas de crescimento, pois a taxa de giro do investimento inovador pode ser alta se comparada com os padrões antigos de produção.

Boserup (1987) alerta que na interpretação quanto à resistência à inovação, os economistas não deveriam abandonar a explicação oferecida por antropólogos e sociólogos antes de investigar se têm diante de si um caso onde a mudança técnica representa rendimentos decrescentes do trabalho, de forma que a resistência não necessitaria ser explicada como ausência de respostas a incentivos econômicos, e sim como uma forma inapropriada frente à demanda de processos gradativos de inovação tecnológica da agricultura familiar.

Para Mattos et al. (2011), a terra agrícola tem os componentes de "qualidades naturais" e de "estrutura de capital", sendo o primeiro determinante de aptidão agrícola e o segundo consequente de investimentos passados. Mattos e Hercowitz (2011) alertam, porém, que essa harmonização entre estrutura de capital e qualidades naturais da terra ainda se apresenta como uma realidade distante do planejamento de políticas públicas federais, apesar dos avanços recentes. Nesse sentido, políticas públicas inovadoras constituem-se como o caminho mais efetivo 
para o acesso à estrutura de capital harmonizada à demanda de sustentabilidade ambiental, como mitigação de desmatamento.

A especificidade ambiental da região amazônica, maior reserva de biodiversidade do planeta, exige uma estratégia de desenvolvimento agrícola compatível com a preservação do maior área possível do bioma. A razão para se reivindicar a preservação quase integral da cobertura florestal da região reside no valor crescente da floresta tropical face ao valor limitado da produção agropecuária, tanto devido à dramática redução das reservas florestais mundiais quanto ao avanço dos conhecimentos científicos que descortinam novas possibilidades de seu uso sustentado da floresta como fonte de biodiversidade e como base de sustentação de processos naturais fundamentais. Nas condições atuais, a análise de custo-benefício indica que o valor presente dos projetos de desenvolvimento agropecuário compensa a substituição da floresta, no entanto, mesmo sem se considerar os possíveis benefícios associados à biodiversidade, o desmatamento implica consideráveis perdas econômicas futuras do valor das espécies, cuja produção poderia ser manejada de modo sustentável. O problema básico é que os benefícios da preservação e manejo são potenciais e não entram no cálculo econômico dos agentes, fato que expõe a demanda por políticas de remuneração de serviços ambientais em escala de paisagem rural (ROMEIRO, 1998; MATTOS, 2010).

Portanto, em lotes familiares rurais amazônicos, as áreas de reserva legal deveriam ser destinadas à regeneração natural e à introdução de sistemas agroflorestais, mas devido à falta de políticas específicas, parte delas é utilizada para a formação de pastagens extensivas. O reflorestamento puro e simples tem poucas chances de sucesso se os produtores familiares não puderem retirar renda, ao passo que sistemas agroflorestais advindos de enriquecimento de capoeiras apresentam potencial de unir agregação de renda e capacidade de restabelecimento da reserva legal (MAT'TOS, 2010; PERZ; WALKER, 2002; GUANZIROLI et al., 2001). Nesse sentido, Pichón (1996) expõe que sem o direcionamento de políticas tecnológicas e infraestrutura para a economia florestal, a conversão de florestas em áreas agrícolas e pecuária envolve um custo de oportunidade que opõe renda familiar anual e reserva legal.

Van Wey et al. (2009) demonstram que a renda doméstica das populações humanas é o fator mais importante que afeta as condições ambientais, sendo as instituições um fator contextual importante que intervém nos efeitos do tamanho e taxa de crescimento de uma população sobre a cobertura florestal. É o que Mattos (2010) encontra no estudo do Proambiente, onde a presença de capital social mais consolidado (conforme definido anteriormente em relação à experiência em projetos e participação em associações comunitárias) em algumas sub-regiões amazônicas propiciou melhor planejamento de uso sustentável da terra e dos recursos naturais. No entanto, mesmo onde há forte institucionalidade, a variável renda mais alta é determinante na promoção do desmatamento.

Para a variável independente "renda familiar anual", Mattos (2010) assumiu como hipótese que o atendimento aos princípios de uso econômico ecológico da terra do Proambiente vem de famílias com renda superior devido à maior capacidade de investimento em sistemas agroecológicos associados com retenção ou recuperação de reserva legal. O autor encontrou relação negativa entre elevação da renda familiar anual e retenção de reserva legal, ou seja, quanto maior é a renda familiar anual, menor é a ocupação proporcional do lote com reserva legal. Em famílias com renda anual de até $\mathrm{R} \$ 20.000,00$ (divididas em oito categorias de renda), $29,77 \%$ a $35,95 \%$ dos lotes concentram mais de $60 \%$ de reserva legal, percentual que cai para apenas $16,79 \%$ dos lotes com renda familiar anual acima de $\mathrm{R} \$ 20.000,00$. O quadro torna-se mais crítico ao se analisar a legalidade ambiental no bioma amazônico (mais de $80 \%$ de reserva legal), onde somente $12,29 \%$ a $18,11 \%$ dos lotes com renda até $\mathrm{R} \$ 20.000,00$ cumprem a exigência, patamar que baixa para 9,49\% dos lotes com renda familiar anual superior a $\mathrm{R} \$ 20.000,00$. Outro ponto destacado no estudo é que conforme se eleva a renda familiar anual, se eleva também o contingente de cultivos perenes e de pecuária de forma equivalente, sendo que a soma das duas áreas se equivalem na retirada de reserva legal. De fato, famílias rurais mais capitalizadas investem mais em sistemas perenes, que garantem maior sustentabilidade ambiental, mas ao mesmo tempo estabelecem com mais força a pecuária, atividade que concorre por espaço com a reserva legal. Para a renda familiar anual, a hipótese não se confirma, o que indica que políticas de estímulo à produção rural necessitam ser integradas às exigências da legislação ambiental, aparecendo como opções os sistemas agroflorestais e agrosilvipastoris.

\section{ACESSO AO CRÉDITO RURAL}

Para Walker e Homma (1996) e Mattos e Uhl (1994), eventuais distorções do acesso ao crédito rural podem impor séria carga financeira aos agricultores 
familiares, levá-los à bancarrota e os direcionarem à inevitável migração para uma nova fronteira agrícola. Porém, os agricultores familiares podem permanecer em seus lotes sob condições apropriadas, sendo a atividade pecuária uma das mais importantes para diminuição de riscos financeiros. Embora as pastagens sejam comumente associadas às grandes corporações agropecuárias, evidências científicas demonstram que reduzidas operações de conversão da terra para uso pecuário são viáveis devido aos seus baixos custos de oportunidades de trabalho e capital, embora impliquem em contingente equivalente de desmatamento

O reconhecimento da importância estratégica da produção familiar rural não seria suficiente para justificar as políticas de apoio financeiro, não fosse a sua capacidade de produzir de maneira eficiente sob o ponto de vista econômico, de absorver progresso técnico e de atender às demandas por alimentos e fibras do setor urbano-industrial (VEIGA, 1991). Parte significativa de produtores familiares brasileiros, dentre eles os mais descapitalizados, que receberam algum tipo de apoio financeiro, sobretudo acesso ao crédito rural sob condições especiais de carência, prazos de amortização e taxas de juros, conseguiu inovar além da pecuária, diversificar seus sistemas produtivos e dar curso a trajetórias bem sucedidas de capitalização (GUANZIROLI et al., 2001). Portanto, é equivocada a visão da agricultura familiar como autossuficiente e avessa ao risco das operações financeiras, pois na prática, a grande maioria necessita de recursos externos para operar suas unidades de maneira mais rentável e sustentável.

No entanto, Mattos (2010) e Norder (2006) ponderam que a demanda por crédito rural da agricultura familiar tende a ser altamente heterogênea num processo integrado de diversificação produtiva e mitigação do desmatamento. $\mathrm{O}$ acesso às linhas de financiamento rural pode proporcionar maior autonomia na produção e uma redução na dependência com determinadas relações de mercado, assim como a inflexibilidade no sistema de crédito rural pode representar um obstáculo adicional à reativação e diversificação das economias locais.

Nesse sentido, um fato de grande repercussão social e política na Amazônia ocorre com a nova Constituição Federal do Brasil de 1988, ao criar os Fundos Constitucionais, que estabeleceu a obrigação da União destinar 3\% da arrecadação nacional do Imposto de Renda (IR) e Imposto sobre Produto Industrializado (IPI) para serem aplicados em programas de financiamento aos setores produtivos das Regiões Norte $(0,6 \%)$, Centro-Oeste $(0,6 \%)$ e Nordeste $(1,8 \%)$. Para a Região Norte foi criado o Fundo Constitucional de Financiamento do Norte (FNO), com programas de financiamento aos setores produtivos privados rurais e industriais (TURA; COSTA, 2000; BASA, 2000).

Mattos (2008; 2010) e Mattei $(2007$; 2001) também registram que, a partir de 1994, outra importante mudança institucional foi desencadeada para atender os interesses da agricultura familiar. Primeiramente, o governo Itamar Franco criou o Programa de Valorização da Pequena Produção Rural (Provap), que tinha como objetivo destinar crédito rural com taxas de juros mais acessíveis aos agricultores familiares, definindo-os como uma categoria única a partir da renda bruta. Embora os resultados do Provap sejam insignificantes, ele cumpriu relevante papel de transição para futura diferenciação de políticas por categorias familiares. Em 1995, já no governo Fernando Henrique Cardoso, o Provap foi totalmente reformulado, dando origem, em 1996, ao Programa Nacional de Fortalecimento da Agricultura Familiar (Pronaf). A partir de 1999, com o início do segundo mandato de Fernando Henrique Cardoso, o Pronaf passou por mudanças institucionais, entre elas, a estratificação dos beneficiários do programa em cinco categorias de renda bruta, permitindo melhor adequação das regras de financiamento às distintas realidades que compõem a agricultura familiar. Em 2003, ano de posse do governo Luiz Inácio Lula da Silva, novas mudanças institucionais são tomadas, como início do aumento significativo do orçamento do Pronaf (em torno de 600\% entre 2003-2010), criação de mais uma categoria de renda bruta, queda das taxas de juros, aumento do período de carência e dos prazos de amortização, medidas importantes para permitir o desencadeamento de processos gradativos de transição produtiva da agricultura familiar. Mais recentemente, em 2008, já no segundo mandato do governo Luiz Inácio Lula da Silva, foram unificadas algumas categorias de renda, com readequação das taxas de juros conforme o intervalo de renda anual de cada mutuário. Esse processo desencadeado entre três diferentes governos de transitam em campos políticos divergentes (sobretudo os dois últimos) demonstra que a iniciativa de criação do Pronaf tem se firmado como o principal programa governamental destinado à agricultura familiar. Assim, o Pronaf deixa de ser uma política circunstancial de governo para se tornar uma relevante política de Estado, com orçamento previsto no ano agrícola de 2009/2010 em torno de R $\$ 16$ bilhões. O que pode ser observado também nos últimos quatro anos agrícolas é que o Pronaf apresenta alta capilaridade ao firmar a maioria de seus contratos com grupos de produtores familiares menos capitalizados, ao mesmo tempo em que dedica a maior parte do seu montante de capital na consolidação dos produtores familiares mais capitalizados. 
Assim como o Pronaf e o FNO, que com suas diversas linhas de financiamento rural oferecem oportunidades para a transição produtiva da agricultura familiar, o Proambiente aparece como importante meio para qualificar essa transição produtiva (e as próprias operações do Pronaf e FNO) a partir do planejamento econômico ecológico integrado, possibilitados pelos seus Planos de Utilização das Unidades de Produção (PUs) e Acordos Comunitários de Serviços Ambientais (ACs), que zelam pela prática produtiva agroecológica e retenção de reserva legal.

Apesar da importância fundamental do surgimento do FNO e Pronaf a partir dos anos 90, Costa (2000) demonstra que a base de investimentos de agricultores familiares do nordeste do estado do Pará (Amazônia brasileira), durante os anos 1980 e 1990, foram os recursos próprios das unidades familiares, exceto nas situações de restrição de trabalho e abundância de terras, onde há um percentual mais significativo de financiamento rural aplicado na pecuária (sob outros tipos de crédito rural que não o FNO e Pronaf). Os investimentos para todos os demais grupos (restrição de trabalho e terras, abundância de trabalho e terras, abundância de trabalho e restrição de terras) fizeram-se com menos de 10\% de financiamento rural (também sob outros tipos que não o FNO e Pronaf).

Para Ludewigs (2006), recentemente, a agricultura tornou-se prioritária na política de crédito rural do FNO devido aos impactos ecológicos reduzidos que causa quando comparada com a pecuária. O agente financeiro do FNO assumiu uma política de restrição à pecuária para evitar a conversão de áreas florestais em pastagens, sendo que uma das estratégias utilizadas fundamenta-se na exigência de compra de animais com certificação de origem, os quais possuem um preço de mercado mais elevado e, consequentemente, desencorajam a tomada do financiamento.

Mas, as relações entre mudanças de uso da terra e crédito rural são complexas de se tratar, não somente por implicar uma ampla gama de condicionantes, mas também porque as linhas de crédito rural variam conforme a política de financiamento do agente financeiro (Mattos, 2010).

Políticas de crédito rural podem ter efeitos positivos e negativos, dependendo das características das mesmas, no desmatamento. A entrada de capital pode suportar a difusão de tecnologias com potencial de reduzir a pressão em áreas florestais tropicais, como observado no Equador, Costa do Marfim e Indonésia, ou de trazer mais desmatamento, como experiências mapeadas no Brasil, Bolívia e Equador (ANGELSEN; KAIMOVITZ, 2001).
O sistema de financiamento rural com isenções fiscais e subsídios do governo militar brasileiro (anos 60-80) para a pecuária extensiva da Amazônia configurou uma relação de elevação do acesso ao crédito rural e diminuição da reserva legal (VAN WEY et al., 2009). Já a institucionalização do Pronaf vem corroborar e a do FNO inverter essa relação entre crédito rural e reserva legal (MATTOS, 2010).

Para Brondízio (2009) e Brondízio et al. (2002), o aumento significativo do desmatamento em lotes familiares da Amazônia brasileira, observado até o ano de 1996, pode ser associado com a estabilização econômica do país e o retorno de incentivos de crédito rural. As trajetórias de desmatamento apresentam um padrão claro para lotes ocupados em diferentes períodos, onde pulsos de desmatamento associados com as culturas anuais e pastagens marcam os ciclos de formação dos lotes. A magnitude desses pulsos de desmatamento relaciona-se à interação entre decisões dos agricultores familiares e efeitos periódicos macroeconômicos, condições institucionais (ex: políticas de financiamento rural) e de infraestrutura (ex: pavimentação de rodovias e abertura aos mercados consumidores).

Portanto, a relação entre tempo de ocupação do lote, crédito rural e desmatamento não é linear. McCracken et al. (1999) lembra que uma série de hipóteses vem sendo desenvolvida para a compreensão de como os agricultores familiares, distintamente, respondem as políticas de crédito rural nas suas estratégias agrícolas. Para Ludewigs et al. (2009), um das mudanças fundamentais que assegura maior equidade na distribuição do crédito rural, prioridade à integração regional e responsabilidade ambiental ocorre com a estruturação do FNO.

Para a variável independente "acesso ao crédito rural”, Mattos (2010) assumiu como hipótese que o atendimento aos princípios de uso econômico ecológico da terra do Proambiente vem de famílias com acesso ao crédito rural, devido à maior capacidade de investimento em sistemas agroecológicos associados com retenção ou recuperação de reserva legal. Vale ressaltar que o estudo do autor não objetivou traçar relações de causa e efeito entre a variável independente "acesso ao crédito rural" e a variável dependente "reserva legal", pois os dados levantados somente informam o tipo de crédito rural tomada pelos mutuários selecionados pelo Proambiente, sem especificar se a vigência do empréstimo encontra-se no prazo de carência, amortização ou quitação, ou seja, a influência do acesso ao agente financeiro pode já ter ou não se manifestado na reserva legal. Portanto, foi apenas proposta a busca de relações entre crédito rural 
e perfis dos lotes quanto ao desmatamento. O estudo encontrou que a reserva legal tem relação negativa com o acesso ao crédito rural do Pronaf e relação positiva com o acesso ao crédito rural do FNO. Dentre os lotes que acessam o crédito rural do Pronaf, apenas 8,24\% estão de acordo com a legislação ambiental amazônica (mínimo de $80 \%$ de reserva legal), contra 20,57\% daqueles com acesso ao crédito rural do FNO. No outro extremo, na classe de porcentagem de $0-20 \%$ de reserva legal situam-se $41,36 \%$ dos lotes com Pronaf e somente $17,02 \%$ com FNO. Nos patamares intermediários predominam os lotes com acesso ao FNO. Assim, no presente estudo, o FNO se demonstrou como uma política de crédito rural mais congruente à legalidade ambiental que o Pronaf, certamente pela sua decisão de financiar sistemas agroflorestais averbáveis como reserva legal. Neste caso estudado, o Pronaf induziu a pecuarização das áreas de reserva legal de maneira mais agressiva que o FNO, que apesar de também expandir a pecuária, demonstra ao mesmo tempo maior capacidade de promover diversificação dos sistemas de produção e propiciar sua averbação como reserva legal. Para o acesso ao crédito rural, a hipótese se confirma para o FNO e não se confirma para o Pronaf. No presente trabalho, lotes com acesso ao crédito rural Pronaf tendem à pecuarização, que em meia parte ocupa áreas de reserva legal, além de apresentar decréscimo de cultivo perenes em relação aos não mutuários. Já lotes com acesso ao crédito rural FNO avançam na pecuarização dos lotes, mas em terça parte em relação ao Pronaf, sendo visível que também induzem o cultivo de perenes e, sobretudo, a contenção de reserva legal em comparação aos não mutuários de crédito rural.

\section{ACESSO À ENERGIA ELÉTRICA PARA BENEFICIAR A PRODUÇÃO}

Inhetvin (2000) expõe que barreiras tecnológicas (inadequação do pacote da Revolução Verde para a agricultura familiar), comerciais (falta de mercados internos com poder aquisitivo), institucionais (escassez de crédito rural) e de infraestrutura (indisponibilidade de redes de transporte, de acesso à energia elétrica e comunicação), assim como uma grande dependência econômica de relativamente poucos produtos, com preços incertos, implicam em uma base instável tanto para o resultado econômico dos estabelecimentos familiares rurais como para sua reprodução social.
Pan et al. (2004) demonstram que o aumento das operações de crédito rural e da oferta de energia elétrica expandiu de 21\% para 73\% em lotes da Amazônia equatoriana próximos de rodovias, o que evidencia a importância de processos logísticos integrados. E como o acesso à infraestrutura eleva o preço da terra, três variáveis adicionais são importantes para viabilizar investimentos de longo prazo na produção familiar e deter a posse da terra: crédito rural (MATTEI, 2007), regularização fundiária (BENATTI, 2003) e tempo de ocupação do lote (ROMEIRO, 1999).

Em estudo de campo, Pan e Bilsborrow (2005) identificaram a importância de variáveis de infraestrutura no uso da terra, bem como a relevância do uso de modelos multivariados para prever tais relações. Diversos estudos com tais modelos traçam essas relações. Pan et al. (2004) encontraram que o acesso à energia elétrica afeta positivamente, e de forma significativa, a diversificação agrícola, enquanto Ludewigs (2006) verificou que o acesso à energia elétrica é extremamente relevante para a expansão de sistemas perenes. Mattos (2010) também identificou a importância do acesso à energia elétrica para a diversificação produtiva baseada em sistemas perenes e para a geração de renda familiar anual, assim como para a retirada de reserva legal. O último autor salienta que o acesso à energia elétrica abre a possibilidade de beneficiamento da produção em packing houses instalados em lotes individuais ou em áreas coletivas (cooperativas, associação de moradores) e garante uma margem temporal de negociação mais ampla aos agricultores familiares, pois diminui a perecibilidade de cultivos perenes, mas potencializa o desmatamento.

Também para Pichón (1996), a energia elétrica agrega valor à terra e torna a produção agrícola mais viável, porém, atrai ocupação humana e especulação imobiliária à fronteira agrícola, consequentemente, desencadeia novos eventos de desmatamento. Da mesma forma, para Alves (2002), o desmatamento tende a ser mais intenso em áreas com disponibilidade de energia elétrica, logo, essa relação de causa e efeito deve ser tomada com particular interesse para a redefinição de políticas públicas de desenvolvimento regional. Para mitigar processos de desmatamento advindos de obras regionais de infraestrutura, Mattos (2010) sugere mecanismos complementares, como aprimoramento de legislação ambiental, criação de unidades de conservação e reservas extrativistas, homologação de terras indígenas, zoneamento econômico ecológico e aprimoramento da capacidade de gestão e fiscalização pública.

Para a variável independente "acesso à energia elétrica", Mattos (2010) assumiu como hipótese que o atendimento aos princípios de uso econômico ecológico da terra do Proambiente vem de famílias com acesso à energia elétrica, 
devido à maior capacidade de investimento em sistemas agroecológicos associados com retenção ou recuperação de reserva legal. O estudo do autor encontrou que a preservação de reserva legal tem relação negativa com o acesso à energia elétrica para beneficiamento da produção. Lotes sem acesso à energia elétrica apresentam maior capacidade de cumprir a legislação ambiental amazônica (mínimo de 80\% de reserva legal), ou seja, 25,33\% deles apresentam-se em conformidade à legislação ambiental, contra somente $2,38 \%$ daqueles com energia elétrica. Ainda restam $26,07 \%$ dos lotes sem acesso à energia elétrica que detém entre $60-80 \%$ de reserva legal e se aproximam da legalidade ambiental, patamar que cai para 7,54\% dos lotes com acesso à energia elétrica. Para o acesso à energia elétrica, a hipótese não se confirma, pois há clara relação entre a presença dessa infraestrutura e o desmatamento de reserva legal. $\mathrm{O}$ acesso à energia elétrica é tanto um indicador de crescimento econômico (pois colabora com a formação de capital, e se comparado ao transporte, em 30\% a mais) quanto de desmatamento de reserva legal, o que demonstra a necessidade de adequação dos instrumentos econômicos (ex: crédito rural e políticas de compra de alimentos regionais) à infraestrutura e legislação ambiental amazônica.

\section{CONCLUSÕES}

Para a variável independente "origem família", que se liga aos aspectos culturais (entre outros fatores), a hipótese foi confirmada, pois lotes liderados por famílias com origem na Amazônia, destacadamente, preservam maior contingente de reserva legal. Entre as variáveis que se ligam aos aspectos econômicos, o "tamanho do lote" e o "acesso ao crédito rural do FNO" também houve confirmação das hipóteses. É nítida a relação positiva entre tamanho do lote e reserva legal, exceto para os lotes com perfil estritamente pecuário familiar, que demandam maiores porções de terra e desencadeiam processos de desmatamento proporcionalmente mais abrangentes. Esse resultado corresponde à demanda dos movimentos sociais rurais de revisão da legislação ambiental aos lotes familiares da região. Para o "acesso ao crédito rural do FNO", é visível que políticas de desenvolvimento econômico para a Amazônia demandam planejamento com foco nas características regionais do bioma. Em situação oposta, para o "acesso ao crédito rural do Pronaf” a hipótese não foi confirmada. Se por um lado, o Pronaf cumpre papel importante de catalisar os processos de capitalização de lotes familiares, por outro, está ainda muito centrado na lógica produtiva restritamente agrícola e pecuária do Centro-Sul do país, ignorando as demandas extrativistas, agroflorestais e agrosilvipastoris da Amazônia. Para as variáveis independentes "tempo de ocupação do lote", "renda familiar anual" e "acesso à energia elétrica" as hipóteses também não se confirmam. No caso do "tempo de ocupação do lote", o presente artigo confirma a relação entre alta rotatividade nos lotes e desmatamento. A entrada de novas famílias nos lotes estabelece novos eventos de desmatamento, ou seja, dentro do ciclo familiar há estabilização do desmatamento ao longo do tempo, mas no ciclo do lote com rotatividade familiar esta especificidade não ocorre. A relação direta do aumento de "renda familiar anual" e do "acesso à energia elétrica" com o desmatamento de reserva legal também evidencia que processos de capitalização e de heterogeneidade estrutural demandam uma logística mais integrada aos quesitos ecológicos da Amazônia. De maneira geral, origem da família, tamanho do lote e acesso à energia elétrica são variáveis independentes muito importantes para a preservação ou não de reserva legal, expondo que fatores culturais, além dos econômicos, devem ser considerados nos processos de desenvolvimento rural da Amazônia brasileira.

Por fim, vale frisar dois pontos. O primeiro é que pesquisas futuras irão desagregar os dados e interpretar a influência de cada variável independente no uso da terra e no desmatamento de cada uma das sete sub-regiões estudadas, além de analisar a influência múltipla entre as variáveis. O segundo é que o presente e os futuros estudos intencionam colaborar não somente com o aprimoramento do Proambiente, mas com eventuais estratégias e políticas integradas de desenvolvimento rural e prestação de serviços ambientais. O Proambiente passou por um processo de esvaziamento profundo do primeiro (2003-2006) para o segundo (2007-2010) mandato do Governo Luiz Inácio Lula da Silva e tende a se extinguir no próximo governo, seja qual for sua tendência política, mas as lacunas de informação que este programa demanda não se remetem apenas ao próprio, mas a um processo de desenvolvimento rural com critérios sociais, culturais, econômicos, ecológicos e políticos mais equilibrados.

\section{AGRADECIMENTOS}

O presente estudo é parte da tese de doutorado realizado no Instituto de Economia (IE) da Universidade Estadual de Campinas (Unicamp) pelo primeiro autor, que agradece o suporte financeiro da Empresa Brasileira de Pesquisa Agropecuária (Embrapa) ao curso de doutorado, trabalho de campo e intercâmbio acadêmico internacional de um ano desenvolvido no Anthropological Center for Training and Research on Global Environmental Change (ACT) da Indiana University (IU), Bloomington, IN, Estados Unidos da América. 


\section{REFERÊNCIAS}

ALVES, D. An Analysis of the Geographical Patterns of Deforestation in the Brazilian Amazon in the Period 1991-1996. In: WOOD C. H.; PORRO, R. (Eds.). Deforestation and land use in the Amazon. Gainsville: University Press of Florida, 2002. p. 133-161.

ANGELSEN, A.; KAIMOWITZ, D. (Eds.). Agricultural Technologies and Tropical Deforestation. Oxfordshire: CABI Publishing, 2001.

ARIMA, E. A distribuição espacial do crédito do FNO no estado do Pará. In: TURA, L.R.; COSTA, F. de A. (Orgs.). Campesinato e estado na Amazônia: impactos do FNO no Pará. Brasília: Brasília Jurídica-FASE, 2000, p. 63-106.

BASA-Banco da Amazônia. Programa de aplicação de recursos 2000 a 2003. Belém: BASA, 2000.

BATISTELLA, M.; ROBESON, S; MORAN, E.F. Settlement Design, Forest Fragmentation, and Landscape Change in Rondônia, Amazônia. Photogrammetric Engineering \& Remote Sensing. v. 69, n. 7, July, p. 805-812, 2003.

BATISTELLA, M. Landscape Change and Land-Use/Land-Cover Dynamic in Rondônia, Brazilian Amazon. Bloomington: Center for the Study of Institutions, Populations and Environmental Change, Indiana University, 200. (CIPEC Dissertation Series, n. 7).

BENATTI, J.H. Direito de Propriedade e Proteção Ambiental no Brasil: apropriação e uso dos recursos naturais no imóvel rural. Tese (Doutorado) Núcleo de Altos Estudos Amazônicos, Universidade Federal do Pará, Belém, 2003.

BOSERUP, E. Evolução Agrária e Pressão Demográfica. São Paulo: Hucitec, 1987.

CARVALHO, V.R.V. Inovação, Diversificação Cultural e Sociabilidade. In: COSTA, F. de A. (Org). Agricultura Familiar em Transformação no Nordeste Paraense: o caso de Capitão Poço. Belém: NAEA/UFPA, 2000.

COSTA, F. de A. Economia Camponesa e Dinâmica Inovativa: o caso eloquente de Capitão Poço. In: COSTA, F. de A. (Org.). Agricultura Familiar em Transformação no Nordeste Paraense: o caso de Capitão Poço. Belém: NAEA/ UFPA, 2000.

DIRVEN, M. Empório rural, grupos etários e genero. In: Ornas, ocupações rurais não agrícolas. Oficina de atualização temática. Londrina: Iapar, 2000.

GRAZIANO DA SILVA, J. Tecnologia e agricultura familiar. Porto Alegre: UFRGS, 1999.
GUANZIROLI, C; ROMEIRO, A; BUAINAIN, A.M; DI SABATTO, A; BITTENCOURT, G.. Agricultura familiar e reforma agrária no século XXI. Rio de Janeiro: Garamond, 2001.

HOFFMANN, R. Elasticidade-renda das despesas e do consumo de alimentos no Brasil em 2002-2003. Brasília:IPEA, 2003.

INHETVIN, T. Produção Camponesa e Redes Mercantis em Capitão Poço. In: COSTA, F. de A. (Org). Agricultura Familiar em Transformação no Nordeste Paraense: o caso de Capitão Poço. Belém: NAEA/UFPA, 2000.

LUDEWIGS, T; D’ANTONA, A.O.; BRONDIZIO, E.S.; HETRICK, S. Agrarian Structure and Land-Cover Change along the Lifespan of Three Colonization Areas in the Brazilian Amazon. World Development, 2009.

LUDEWIGS, T. Land-Use Decision Making, Uncertainty and Effectiveness of Land Reform in Acre, Brazilian Amazon. Dissertation ( PhD in Environmental Science) - School of Public and Environmental Affairs, Indiana University, Bloomington, 2006.

MATTEI, L. Políticas de apoio ao desenvolvimento da agricultura familiar no Brasil: o caso recente do Pronaf. Revista Econômica do Nordeste, Fortaleza, v.38, n`1, jan-mar. 2007.

MATTEI, L. Programa Nacional de Fortalecimento da Agricultura Familiar (Pronaf): concepção, abrangência e limites observados. In: ENCONTRO DA SOCIEDADE BRASILEIRA DE SISTEMAS DE PRODUÇÃO, 4. 2001, Belém. MORAN, E.F.; BRONDIZIO, E.S.; BATISTELLA, M. Trajetórias de Desmatamento e Uso da Terra na Amazônia Brasileira: uma análise multiescalar. In: BATISTELLA, M.; MORAN, E.F.; ALVES, D.S. (Orgs.). Amazônia: natureza e sociedade em transformação. São Paulo: EDUSP, 2009.

MORAN, E.F. Developing the Amazon. Bloomington: Indiana University Press, 1981. 292p.

MATTOS, L. Decisões sobre uso da terra e dos recursos naturais na agricultura familiar amazônica: o caso do Proambiente. 380f, 2010. Tese (Doutorado). Campinas: Instituto de Economia, Universidade Estadual de Campinas (Unicamp), 2010.

MATTOS, L.; ROMEIRO, A.R.; HERCOWITZ, M. Economia do meio ambiente. In: MATTOOS, L.; HERCOWITZ, M. (Orgs.). Economia do meio ambiente e serviços ambientais: estudo aplicado à agricultura familiar, populações tradicionais e povos indígenas. Brasília: Embrapa, 2011. No prelo. 
MATTOS, L.; HERCOWITZ, M. Pontos fundamentais para o desenho de políticas públicas de serviços ambientais voltadas às populações tradicionais e povos indígenas. MATTOS, L.; HERCOWITZ, M. (Org.). Economia do meio ambiente e serviços ambientais: estudo aplicado à agricultura familiar, populações tradicionais e povos indígenas. Brasília: Embrapa, 2011. No prelo.

MATTOS, L. Qualificação do Sistema Nacional de Crédito Rural: da política universal (1965-1994) à política diferenciada para a agricultura familiar brasileira (1995-2007). Trabalho apresentado para conclusão de curso "CT-139 Ciência, Tecnologia e Desenvolvimento Agrícola”. Campinas: Unicamp/IG, 2008.

MATTOS, M.; UHL, C. Economic and ecologic perspectives on ranching in the Eastern Amazonia. World Development, v. 22, n. 2, p. 145-158, 1994.

McCRACKEN, S.D.; SIQUEIRA, A., MORAN, E. F.; BRONDÍZIO, E. S. Land use patterns on an agricultural frontier in Brazil; Insights and examples from a demographic perspective. In: WOOD, C. H.; PORRO, R. (Eds.). Deforestation and land use in the Amazon. Gainsville: University Press of Florida, 2002. p.162-192.

McCRACKEN, S.D.; BRONDÍZIO, E. S.; NELSON, D.; MORAN, E. F.; SIQUEIRA, A. D.; RODRIGUEZ-PEDRAZA, C. Remote sensing and GIS at farm property level: Demography and deforestation in the Brazilian Amazon. Photogrammetric Engineering \& Remote Sensing, v. 65, n. 11, p. 1311-1320, 1999.

MORAN, E.F.; BRONDIZIO, E.S.; BATISTELLA, M. Trajetórias de Desmatamento e Uso da Terra na Amazônia Brasileira: uma análise multiescalar. In: BATISTELLA, M.; MORAN, E.F.; ALVES, D.S. (Orgs.). Amazônia: natureza e sociedade em transformação. São Paulo: EDUSP, 2009.

MORAN, E.F.; BRONDÍZIO, E.S.; MCCRACKEN, S. Trajectories of land use: Soils, succession, and crop choice. In WOOD, C.H.; PORRO, R. (Eds.). Land use and deforestation in the Amazon Gainsville: University Press of Florida Press, 2002. p. 193-217.

MORAN, E.F. Developing the Amazon. Bloomington: Indiana University Press, 1981. 292p.

NORDER, L. A. C. Mercantilização da agricultura e desenvolvimento sustentável. In: SCHNEIDER, S. (Ed.). A diversidade da agricultura familiar. Porto Alegre: Editora da UFRGS, 2006. p. 57-81.
PAN, W.K.; CARR, D.; BARBIERI, A; BILSBORROW, R; SUCHINDRAN, C. Forest cleaning in the Ecuadorian Amazon: a study of patterns over space and time. Population Research and Policy Review, v. 26, n. 5-6, p. 635-659, 2007. PAN, W. K. Y.; BILSBORROW, R. E. The use of a multilevel statistical model to analyze factors influencing land use: A study of the Ecuadorian Amazon. Global and Planetary Change, v. 47, p. 232-252, 2005.

PAN, W. K. Y.; WALSH, S. J.; BILSBORROW, R. E.; FRIZZELLE, B. G.; ERLIEN, C. M.; BAQUERO, F. Farm-level models of spatial patterns of land use and land cover dynamics in the Ecuadorian Amazon. Agriculture Ecosystems \& Environment, v. 101, p. 2-3, 117-134, 2004.

PERZ, S. G. Household demographic factors as life cycle determinants of land use in the Amazon. Population Research and Policy Review, v. 20, n. 3, p.159186, 2001.

PERZ, S. G.; WALKER, R. Household life cycles and secondary forest cover among small farm colonists in the Amazon. World Development, v. 30, n. 6, p. 1009-1027, 2002.

PICHON, F. J. Settler agriculture and the dynamics of resource allocation in Frontier Environments. Human Ecology, v. 24, n.3, p. 341-371, 1996.

RAMOS, P. Propriedade, estrutura fundiária e desenvolvimento rural. Estudos Avançados, v. 15, n. 43, 2001.

REARDON, T; CRUZ, M.H.; BERDEGUÉ, J. Los pobres en el desarrollo del empreo rural no agricola en America Latina: paradoja y desafios. In: SIMPOSIO LATINOAMERICANO SOBRE INVESTIGACIÓN Y EXTENSIÓN EN SISTEMAS AGROPECUARIOS, 3. Lima, 1998.

ROMEIRO, A.R.. Meio ambiente e produção agropecuária na Amazônia. Revista de Economia e Sociologia Rural, Rio de Janeiro, v. 37, n. 1, 1999. p. 9-33.

ROMEIRO, A.R. Agricultura Familiar em Áreas de Reforma Agrária: Síntese Regional - Região Norte. Brasília: FAO/INCRA, 1998.

SCHMINK, M.; WOOD, C. Contested Frontiers of Amazonia. New York: Columbia University Press, 1992.

SCHULTZ, T. W. A transformação da agricultura tradicional. Rio de Janeiro: Zahar, 1965. 207 p.

SMITH, N. Rainforest Corridors. Berkeley: University of California Press, 1982. 248p. 
TEDESCO, J.C. Contratualização e racionalidade familiar. 3. Ed. In: TEDESCO, J.C. (Org.). Agricultura familiar: realidades e perspectivas. Passo Fundo: EDIUPF, 2001. 406 p.

TURA, L; MATTOS, L. Financiamento da transição para a agroecologia: a proposta do PROAMBIENTE. In: ENCONTRO NACIONAL DE AGROECOLOGIA (ENA). Rio de Janeiro, 2002.

VAN DER PLOEG, J.D. O modo de produção camponês revisitado. In: SCHNEIDER, S. (Org). A Diversidade da Agricultura Familiar. Porto Alegre: UFRGS, 2006.

VAN WEY, L.K.; OSTROM, E.; MERETSKY, V. Teorias subjacentes ao estudo de interações homem-ambiente. In: MORAN, E.F.; OSTROM, E. (Orgs.). Ecossistemas florestais: interação homem-ambiente. Tradução Alves, D.S. e Batistella, M. Sao Paulo: SENAC, Edusp, 2009.

VAN WEY, L.K.; D’ANTONA, A; BRONDIZIO, E.S. Household Demographic Change and Land Use / Land Cover Change in the Brazilian Amazon. Population and Environment, n. 28, p. 163-185, 2007.

VEIGA, J.E. O desenvolvimento agrícola: uma visão histórica. São Paulo: EDUSP; HUCITEC, 1991.

WALKER, R. Mapping process to pattern in the landscape change of the Amazonian frontier. Annals of the Association of American Geographers, v. 93, n. 2, p. 376-398, 2003.

WALKER, R.; PERZ, S.; CALDAS, M.; SILVA, L. G. T. Land use and land cover change in forest frontiers: The role of household life cycles. International Regional Science Review, v. 25, n. 2, p. 169-199, 2002.

WALKER, R. T.; HOMMA, A. K. O. Land use and land cover dynamics in the Brazilian Amazon: an overview. Ecological Economics, v. 18, p. 67-80, 1996. WOORTMANN, K. Com parente não se neguceia. Anuário Antropológico, Brasília, n. 84, p. 11-73, 1990.

Texto submetido à Revista em 17.3.2010

Aceito para publicação em 3.10.2010 